\title{
The TIMI Study Group's Contributions to the Advancement of Cardiology -With Focus on Atherosclerotic Cardiovascular Disease-
}

\author{
Eri Toda Kato ${ }^{1}$ and Shinya Goto ${ }^{2}$
}

${ }^{1}$ Department of Cardiovascular Medicine, Kyoto University Hospital, Kyoto, Japan

${ }^{2}$ Department of Medicine (Cardiology), Tokai University School of Medicine, Kanagawa, Japan

Atherosclerotic cardiovascular disease (ASCVD) is the leading cause of morbidity and mortality across the world, warranting continuous research in this field. The elucidation of the atherogenesis mechanism is considered one of the most relevant scientific accomplishments of the last century. This has led to the clinical development of various novel therapeutic interventions for patients with or at risk of ASCVD, in which randomized clinical trials played a crucial role.

The Thrombolysis in Myocardial Infarction (TIMI) Study Group was initially established to conduct a clinical trial studying thrombolysis for treatment of myocardial infarction. However, over the years, the TIMI Study Group has expanded their research interests to include antithrombotic therapy, lipid lowering, antidiabetes, anti-obesity, and even heart failure. By leading large-scale, international, randomized, controlled trials of novel therapeutics, the TIMI Study Group has helped shape the very practice of cardiovascular medicine for over a quarter of a century, and decades of research continue to provide future promise for further advancement. Through a mutual goal to improve the care of ASCVD patients, the Japanese scientific community has become one of the important contributors to the TIMI Study Group's clinical research.

In this review article, the authors aim to summarize major research lead by the TIMI Study Group in the ASCVD field.

Key words: Atherosclerosis, Cardiovascular diseases, Lipid lowering, Antithrombotic, TIMI

\section{Introduction}

There has been substantial scientific progress in the understanding of the pathophysiology and treatment of atherosclerotic cardiovascular disease (ASCVD) over the last century, which we owe to decades of basic research and to the upsurge of refined and sophisticated clinical research led by academic research organizations (AROs).

The term ARO refers to an academic or nonprofit organization which focuses on developing clinical evidence systematically to improve patient care across the globe. AROs consist of teams of academic investigators aiming to conduct clinical research to address clinical questions and unmet needs, and to educate the next generation of clinical investigators to raise the level of overall clinical research, including clinical trials.

The concept of AROs dates to the 1980s when a few groups started academic international clinical studies. The one group in particular that has paved the way is the Thrombolysis in Myocardial Infarction (TIMI) Study Group at Brigham and Women's Hospital and Harvard University, along with others such as Duke Clinical Research Institute (DCRI) at Duke University, Clinical Trial Service Unit (CTSU) at the University of Oxford, and the Population Health Research Institute at McMaster University. Since high quality clinical research requires a lot of resources, important clinical trials were initially sponsored by the National Heart, Lung, and Blood Institute (NHLBI), which is part of the United States Department of Health \& Human Services (DHHS). The TIMI Study Group was established in 1984 and

Address for correspondence: Eri Toda Kato, Department of Cardiovascular Medicine, Kyoto University Hospital, 54 Shogoin-kawaramachi, Sakyo-ku, Kyoto, Japan E-mail: erikato@kuhp.kyoto-u.ac.jp

Received: February 8, $2021 \quad$ Accepted for publication: February 24, 2021

Copyright@2021 Japan Atherosclerosis Society

This article is distributed under the terms of the latest version of CC BY-NC-SA defined by the Creative Commons Attribution License. 
was among the first groups to take on the challenge of organizing and implementing global clinical trials. The TIMI Study Group has been the leading figure since then, conducting more than 70 multicenter cardiovascular clinical trials, initially under the leadership of Dr. Eugene Braunwald and later under Dr. Marc S. Sabatine. Currently, the TIMI Study Group's research interests are not only limited to public sector sponsored trials, but also cover new drug developmental studies sponsored by private sectors. Their studies range from phase I to phase IV trials, registries, and from small domestic studies to mega international studies conducted in collaboration with more than 5,000 sites in 50 countries, and have enrolled, in total, approximtely 400,000 patients (Table 1). Their high-quality trial conduct has advanced clinical research and their solid evidence has directed systemic changes to the standard of contemporary cardiovascular practice.

The initial TIMI trial focused on fibrinolytic agents, as evidenced by the group's name. Indeed, fibrinolytic therapy was one of the biggest advances in cardiology-related research, especially before the establishment of catheter-based reperfusion therapy. Even though they still use the term "thrombolysis" in their name, TIMI's research interests have expanded to cover other aspects of ASCVD, including antithrombotic, antiplatelet, anti-ischemic, lipid lowering, anti-inflammatory, anti-obesity and antidiabetic, and even anti-heart failure agents. In this review article, we will summarize some of the major trials led by the TIMI Study Group that have contributed to advances in care of patients with ASCVD.

\section{Antithrombotic Treatment}

Fibrinolytic therapy was a true breakthrough in the late $20^{\text {th }}$ century. Indeed, cardiologists were not certain whether coronary arterial thromboses detected in autopsy patients were the cause or result of acute myocardial infarction (MI). A randomized trial demonstrated the efficacy of antiplatelet agent, aspirin and fibrinolytic agent, streptokinase in prevention of cardiovascular $(\mathrm{CV})$ death in patients who had acute MI within 24 hours ${ }^{1)}$. Aspirin became widely used in acute MI as an antiplatelet therapy, but that was not true for streptokinase due to various limitations. The most advanced biomedical technology at the time was to produce recombinant proteins such as the fibrinspecific fibrinolytic agent of tissue type plasminogen activator $(\mathrm{t}-\mathrm{PA})^{2)}$. Theoretically, intra-venous injection of fibrin-specific fibrinolytic agents should achieve clot lysis more efficiently than non-fibrin-specific agents; however, the validity of this hypothesis needed to be tested by clinical trials. The TIMI Study Group's first clinical trial compared the effect of fibrin-specific t-PA with non-fibrin-specific streptokinase in patients with acute $\mathrm{MI}^{3)}$. Patients treated with t-PA had more successful reperfusion of occluded coronary arteries at 90 minutes compared to patients treated with streptokinase (62\% vs $31 \%$, respectively, $p<0.001$ ). Currently, percutaneous coronary intervention (PCI) is the primary choice for acute MI patients; however, the first TIMI trial remains as an important milestone in the history of ASCVD treatment, providing evidence of salutary effects of early reperfusion on survival, ventricular function, and infarct size.

\section{Antiplatelet Treatment}

Platelet aggregation should be considered the key pathophysiological component in the development of ischemic events, particularly in MI, since coronary occlusive thrombi always contain platelets ${ }^{4)}$. Although its antiplatelet mechanism of action was not completely understood, aspirin has been the unwavering choice for patients with MI, and the center of research was its adjunctive therapy.

Despite the mechanism of action not being known at that time (it was clarified $l a t e r^{5)}$ ), clopidogrel, a safer successor of ticlopidine, was widely used in atherothrombotic patients (coronary artery disease: CAD, cerebrovascular disease: CVD, and peripheral artery disease: PAD) after a favorable result from the CARPRIE randomized clinical trial ${ }^{6}$. Yet the potential role of clopidogrel as adjunctive therapy with thrombolytic agents was not clarified. The TIMI Study Group conducted the Clopidogrel as Adjunctive Reperfusion Therapy (CLARITY- TIMI 28) comparing the addition of clopidogrel with placebo in patients with ST-elevation MI (STEMI) receiving fibrinolytic therapy and aspirin ${ }^{71}$. As expected, the addition of clopidogrel resulted in a significant reduction of infarct-related artery patency, death, or recurrent MI compared to placebo $(21.7 \%$ vs. $15 \%$, respectively, 95\% confidence interval [CI] 24-47\%, $p$ $<0.001)$. Although the widespread use of PCI drastically changed the standard of care for patients with STEMI ${ }^{8)}$, this trial's results added clopidogrel to STEMI management.

After the molecular target of clopidogrel, namely the P2Y 12 ADP receptor, was unraveled ${ }^{5)}$, two of the novel $\mathrm{P}_{2} \mathrm{Y}_{12}$ ADP receptor antagonists were brought to the final stage of clinical development. Clopidogrel is a prodrug and its active metabolite(s) are hard to detect. For treating acute phase MI, delayed onset of antiplatelet activity may cause a problem. 
Table 1. TIMI TRIALS

\begin{tabular}{|c|c|c|c|}
\hline TRIAL NAME & INDICATION & TRIAL NAME & INDICATION \\
\hline TIMI (1) & STEMI & PROMPT - TIMI 35 & Stable CAD \\
\hline TIMI 2B & STEMI & TIMI - 37 & STEMI \\
\hline TIMI 3A & NSTE-ACS & TRITON - TIMI 38 & PCI in ACS \\
\hline TIMI 3B & NSTE-ACS & EARLY ACS - TIMI 39* & NSTE-ACS w/ INV Rx \\
\hline TIMI 4 & STEMI & PLATO ${ }^{\ddagger} \S$ & ACS \\
\hline TIMI 5 & STEMI & SEPIA-ACS1 - TIMI 42 & NSTE-ACS w/ INV Rx \\
\hline TIMI 6 & STEMI & AVANT GARDE - TIMI 43 & Post-ACS \\
\hline TIMI 7 & UA & PRINCIPLE - TIMI 44 & Elective PCI \\
\hline TIMI 8 & NSTE-ACS & VERIFY Pre-Op - TIMI 45 & CABG \\
\hline TIMI 10B & STEMI & TRA $2^{\circ} \mathrm{P}-$ TIMI 50 & Stable ASCVD \\
\hline ASSENT 1 - TIMI $10 \mathrm{C}^{\dagger}$ & STEMI & ATLAS ACS2 - TIMI 51 & Post-ACS \\
\hline TIMI 11A & NSTE-ACS & SOLID - TIMI 52 & Post-ACS \\
\hline TIMI 11B & NSTE-ACS & SAVOR - TIMI 53" & Diabetes \\
\hline TIMI 12 & Post-ACS & PEGASUS - TIMI 54 & Prior MI \\
\hline TIMI 14 & STEMI & REVEAL HPS3/TIMI 55 & Stable ASCVD \\
\hline TIMI $15 \mathrm{~A}$ & ACS & ELEVATE - TIMI 56 & Stable CAD \\
\hline TIMI 15B & ACS & LAPLACE - TIMI 57 & Dyslipidemia \\
\hline OPUS-TIMI 16 & ACS & DECLARE - TIMI $58 \|$ & Diabetes \\
\hline InTIME II - TIMI 17 & STEMI & FOURIER - TIMI 59 & Stable ASCVD \\
\hline ENTIRE - TIMI $23^{\dagger}$ & STEMI & Ongoing Trials & \\
\hline FASTER - TIMI $24^{*}$ & STEMI & FOURIER OLE & Stable ASCVD \\
\hline ExTRACT - TIMI 25 & STEMI & FOURIER LEGACY & Stable ASCVD \\
\hline JUMBO - TIMI 26 & PCI & ORION-4 / HPS4 / TIMI 65 & Stable ASCVD \\
\hline PROXIMATE - TIMI 27 & Stable CAD & VESALIUS-CV - TIMI 66 & Stable Atherosclerosis or Diabetes \\
\hline CLARITY - TIMI 28 & STEMI & OCEAN(a)-DOSE - TIMI 67 & Stable Atherosclerosis \\
\hline ADVANCE MI - TIMI 29* & STEMI & DAPA ACT HF - TIMI 68 & Acute HFrEF \\
\hline PROTECT - TIMI 30 & PCI for NSTE-ACS & GOLDILOX - TIMI 69 & Prior MI \\
\hline TIMI 31 & STEMI & TRANSLATE - TIMI 70 & Dyslipidemia \\
\hline ANTHEM - TIMI 32 & NSTE-ACS & AZALEA - TIMI 71 & Atrial Fibrillation \\
\hline DISPERSE2 - TIMI 33 & NSTE-ACS & COVID-PACT & Critically Ill COVID-19 \\
\hline
\end{tabular}

In conjunction with Leuven Coordinating Center, Belgium

\# In conjunction with Duke Clinical Research Institute

\& In conjunction with Uppsala Clinical Research Center, Sweden

"In conjunction with Hadassah Medical Organization, Israel

'In conjunction with Oxford University, United Kingdom

$\mathrm{ACS}=$ Acute Coronary Syndrome; $\mathrm{ASCVD}=$ Atherosclerotic Cardiovascular Disease; $\mathrm{CABG}=$ Coronary Artery Bypass Grafting; CAD = Coronary Artery Disease; HFrEF = Heart Failure with Reduced Ejection Fraction; INV Rx=Invasive Strategy; LMWH=Low Molecular Weight Heparin; MI = Myocardial Infarction; NSTE-ACS = Non-ST-elevation ACS; PCI=Percutaneous Coronary Intervention; STEMI=ST-elevation myocardial infarction; $\mathrm{UA}=$ unstable angina 
Theoretically, the rate-limiting enzyme in the production of the active metabolite(s) of clopidogrel is the isozyme of cytochrome P450 (CYP) enzyme, namely CYP2C19. The TIMI Study Group conducted genotype-based sub-analyses to demonstrate that the loss-of-function allele in the CYP2C19 genotype, which is present in approximately one-third of the population, was associated with poorer clopidogrel metabolism, lower platelet inhibition, and higher risk of major adverse cardiac events (MACE) ${ }^{9)}$. This is a good example that the TIMI Study Group is always aiming to lead a new research field such as genotypebased personalized medicine using genetic CYP2C19 polymorphism testing or using platelet functional testing to identify poor clopidogrel metabolizers. Hence, more potent antiplatelet agents were explored.

Later, the TIMI Study Group conducted the TRITON-TIMI 38 trial comparing one of the novel $\mathrm{P} 2 \mathrm{Y}_{12}$ inhibitors of prasugrel with clopidogrel in 13,608 patients with acute coronary syndromes (ACS). Prasugrel therapy significantly reduced MACE by $19 \%$ (hazard ratio [HR] 0.81, 95\% CI 0.73-0.99, $p<0.001$ ) and stent thrombosis by $52 \%$ (HR 0.48 , 95\% CI 0.36-0.64, $p<0.0001)$, but with increased risk of major bleeding (HR 1.32, 95\% CI 1.03-1.68, $p=0.03$ ) and intracranial bleeding in patients with prior stroke ${ }^{10)}$. The trial results provided important information for risk-benefit balance in the antiplatelet intervention.

In addition to the $\mathrm{P}_{2} \mathrm{Y}_{12} \mathrm{ADP}$ receptor antagonists, another important platelet-specific receptor of protease-activated receptors (PARs) was identified in the $21^{\text {st }}$ century ${ }^{11)}$. The TIMI Study Group conducted the Thrombolysis in Myocardial Infarction 50 (TRA $2^{\circ}$ P-TIMI 50) trial evaluating the efficacy and safety of vorapaxar, a proteaseactivated receptor (PAR-1), in 26,449 patients with a history of $\mathrm{MI}$, ischemic stroke, or $\mathrm{PAD}^{12)}$. At three years, there was a significant $13 \%$ reduction of MACE (HR 0.87, 95\% CI 0.80-0.94, $p<0.001$ ); however, there was an excess of intracranial hemorrhage (ICH) observed with the treatment of vorapaxar compared with placebo in patients with prior stroke $(1.0 \%$ vs $0.5 \%$, respectively, $p<0.001$ ), which prompted the Data and Safety Monitoring Board (DSMB) to recommend early discontinuation of study treatment in this group.

Prior studies have consistently shown an increased incidence of ischemic events after dual antiplatelet regimen being discontinued, particularly in patients with history of MI. A more potent, reversibly-binding, direct-acting $\mathrm{P} 2 \mathrm{Y}_{12}$ antagonist, ticagrelor, was studied in the PEGASUS-TIMI 54 trial $^{13)}$. The study randomized 21,162 patients with a history of MI to ticagrelor $90 \mathrm{mg}$ twice-daily, or 60 mg twice-daily, or to placebo. All patients received low dose aspirin, and, given prior experience, patients with history of ischemic stroke and ICH were excluded. The two ticagrelor doses had significantly lower rates of MACE at three years (ticagrelor $90 \mathrm{mg}-\mathrm{HR} 0.85$, 95\% CI 0.75-0.96, $p=0.008$; ticagrelor $60 \mathrm{mg}-\mathrm{HR}$ $0.84,95 \%$ CI $0.74-0.95, p=0.004)$. The risk of major bleeding doubled in patients treated with ticagrelor; however, the rates of $\mathrm{ICH}$ or fatal bleeding did not differ with the placebo group.

Lastly, a trial that is worth mentioning is Anti-Xa Therapy to Lower Cardiovascular Events in Addition to Standard Therapy in Subjects With Acute Coronary Syndrome-Thrombolysis in Myocardial Infarction 51 (ATLAS ACS2-TIMI 51) ${ }^{14}$. The trial randomized 15,526 patients receiving low dose aspirin after ACS to receive $2.5 \mathrm{mg}$ rivaroxaban twice-daily, $5 \mathrm{mg}$ rivaroxaban twice-daily, or placebo. The lower dose rivaroxaban regimen resulted in a $16 \%$ reduction of MACE (HR 0.84, 95\% CI 0.74-0.96, $p=0.008$ ) and a 34\% reduction in CV death. These results opened the door to adding a very low dose of an anticoagulant to dual antiplatelet therapy after ACS, MI/PAD, or after PAD intervention and further provided evidence for an anticoagulant monotherapy in patients with atrial fibrillation receiving $\mathrm{PCI}^{15)}$.

Of note, with the advancement in devices and PCI techniques, there is a trend for a shorter dual antiplatelet therapy period and the identification of high bleeding risk patients at the time of writing. Recent trials such as STOPDAPT ${ }^{16)}$, SMART$\mathrm{CHOICE}^{17)}$, and TWILIGHT ${ }^{18)}$ have all demonstrated lower bleeding rates with preserved efficacy in patients with shorter dual antiplatelet therapy (antiplatelet monotherapy) after PCI.

\section{Lipid Management}

Atherosclerosis starts early in life and progresses slowly over time. It is a multifactorial process regulated by a complex interplay between established risk factors. Compelling evidence from experimental studies, epidemiologic observations, and randomized trials of low-density lipoprotein cholesterol (LDL-C) reduction supports the role of LDL-C as a key pathogenesis of ASCVD, and LDL-C lowering remains the primary treatment target for ASCVD.

Dr. Akira Endo discovered the first statin, ML-236B (compactin), in 1976 from the fungi Penicillium citrinum. ML-236B inhibits HMG-CoA reductase, which is an enzyme critical to the ratelimiting step of the cholesterol synthesis pathway ${ }^{19-21)}$. Statins reduce LDL-C levels, reduce inflammation, 
and improve endothelial dysfunction, thereby reducing the adverse cardiovascular events in patients with or without a history of CAD. Dr. Endo's pioneering work in discovery of statins has been recognized as a major milestone to the prevention and treatment of ischemic disease, saving millions of lives worldwide.

Current evidence supports the concept of the "lower the better" for LDL-C. The risks for CV events are reduced by $20 \%$ per $39 \mathrm{mg} / \mathrm{dL}$ reduction of LDL$\mathrm{C}$, but "how much lower" is still being debated.

The Pravastatin or Atorvastatin Evaluation and Infection Therapy-Thrombolysis in Myocardial Infarction 22 (PROVE IT-TIMI 22) trial was designed to investigate whether lower LDL-C levels would increase the clinical benefit. The trial compared intensive statin therapy (atorvastatin $80 \mathrm{mg}$ daily) with standard statin therapy (pravastatin $40 \mathrm{mg}$ daily) in 4,162 patients after ACS ${ }^{22)}$. Patients randomized to the intensive lipid-lowering arm achieved a median LDL-C of $62 \mathrm{mg} / \mathrm{dL}$ whereas the achieved median LDL-C level of the standard statin therapy group was $95 \mathrm{mg} / \mathrm{dL}$. An LDL-C level of $65 \mathrm{mg} / \mathrm{dL}$ was considered extremely low at that time; however, the patients in the intensive statin therapy group had significantly lower risk of death, MI, or urgent revascularization compared with the standard therapy (HR 0.84, 95\% CI 0.74-0.95, $p<0.001$ ), and 25\% reduction in death, MI, and stroke. These results dramatically changed the scene. In addition, the benefit of more intensive lipid lowering appeared within the first month, the finding which indicated that patients benefit from early and continued lowering of LDL-C.

Another epoch-making trial was the Improved Reduction of Outcomes: Vytorin Efficacy International Trial (IMPROVE-IT- TIMI 40 trial) ${ }^{23)}$. The trial aimed to evaluate whether the addition of non-statin ezetimibe to simvastatin improves $\mathrm{CV}$ outcomes compared with simvastatin monotherapy in post-ACS patients. Statins lower cholesterol by upregulating hepatic LDL receptors, whereas ezetimibe inhibits intestinal absorption of cholesterol mainly by blocking Niemann-Pick C1-like 1 protein (NPC1L1). The trial randomized 18,144 patients and the achieved median LDL-C level was $53.7 \mathrm{mg} / \mathrm{dL}$ for the combination therapy and $69.5 \mathrm{mg} / \mathrm{dL}$ for the monotherapy. At seven years, ezetimibe was safe and well-tolerated and showed incremental benefits by lowering the composite endpoint of CV death, nonfatal MI, unstable angina, coronary revascularization, or non-fatal stroke (HR 0.94, 95\% CI 0.89-0.99, $p=0.016)$. This result was in line with the CV risk reduction observed with statin monotherapy, providing evidence that the quantity of LDL-C level reduction is more important than how it is lowered. With a long follow-up, the trial results reinforced the importance of LDL-C lowering in ASCVD patients, and further provided pharmacological options to statin-intolerant patients or patients with familial hypercholesterolemia.

Although LDL-C reduction with statins and non-statins reduces subsequent $\mathrm{CV}$ events, there are substantial residual risks attributable to LDL-C, particularly in patients with ASCVD. Proprotein convertase subtilisin/kexane 9 (PCSK9) inhibitors are innovative therapeutic options in the lipid-lowering treatment that were only identified in 2003 from a French family with familial hypercholestrolemia ${ }^{24)}$. Rooted in genetic studies, PCSK9 research has helped foster the understanding of cholesterol metabolism. PCSK9 is synthesized predominantly in the liver as a $75 \mathrm{kDa}$ proprotein. PCSK9 binds to the LDL receptor (LDL-R) leading to the degradation of the LDL-R, therefore leading to less hepatic removal of LDL-C from the circulation, and higher plasma LDL-C levels ${ }^{23)}$. Both statins and PCSK9 inhibitors reduce LDL-C levels by approximately $60 \%$, and apoB levels by approximately $50 \%{ }^{23,25)}$. However, comparatively, statins are more effective in reducing triglyceride levels whereas PCSK9 further reduces lipoprotein (a) levels. Statins also reduce CRP levels whereas PCSK9 inhibitors have no effect.

The Further Cardiovascular Outcomes Research With PCSK9 Inhibition in Patients With Elevated Risk (FOURIER trial), was the first of the randomized, controlled cardiovascular outcomes trials to assess the effectiveness and safety of PCSK9 inhibitor evolocumab. The trial randomly assigned 27,564 patients to evolocumab, a fully humanized monoclonal antibody that inhibits PCSK9, or to placebo. Compared with standard therapy alone, the addition of evolocumab to the background statin therapy reduced the level of LDL-C by $59 \%$, from a median of $92 \mathrm{mg} / \mathrm{dL}$ to $30 \mathrm{mg} / \mathrm{dL}$ at 48 weeks, which translated into a significant $15 \%$ reduction of CV death, MI, stroke, hospitalization for unstable angina, or coronary revascularization (HR 0.85 , 95\% CI 0.79 $0.92, p<0.001)^{25)}$. The trial results once again reiterated the "lower the better" hypothesis with LDLC. Overall, the treatment was well-tolerated and was approved by the United States Food and Drug Administration (FDA) in record-breaking time, marking a new era of drug discovery with genetics.

Although the benefits of intensive LDL-Clowering therapy have been established, concerns have been raised for the safety of this strategy. A subsequent meta-analysis and sub-analyses demonstrated that very 
low levels of LDL-C (even $<40 \mathrm{mg} / \mathrm{dL}$ ) can be achieved safely, and that those patients had an even greater reduction in adverse cardiovascular outcomes, supporting the "lower the better" hypothesis ${ }^{26-29)}$. Similarly, the 971 patients with achieved LDL-C levels of $<30 \mathrm{mg} / \mathrm{dL}$ in the IMPROVE-IT trial had no excess safety concerns ${ }^{30}$. Challenging even further, the 2,669 patients who achieved LDL-C levels $<20 \mathrm{mg} /$ $\mathrm{dL}$ in the FOURIER trial had no major safety concerns, reassuring the safety of targeting very low LDL-C levels ${ }^{29)}$.

In contrast to LDL-C, high-density lipoprotein cholesterol (HDL-C) has anti-atherogenic properties by removing excess cholesterol from macrophages and transferring them to the liver for bile salt formation. HDL-C also improves endothelial function by increasing the production of endothelial nitric oxide synthase. Epidemiological and observational studies have consistently shown an inverse association between HDL-C levels and CV risks; however, randomized trials to date have failed to show clinical benefit of raising HDL-C levels.

Cholesteryl ester transfer protein (CETP) raises HDL-C and lowers LDL-C, apoB, and lipoprotein(a) by facilitating exchange of esterified cholesterol from HDL-C to very low-density lipoprotein (VLDL) and low-density lipoprotein (LDL). By virtue, CETP inhibitors have received considerable attention as potential new agents for CV prevention. The HPS3/ REVEAL-TIMI 55 trial was conducted in collaboration with the University of Oxford and assessed the effect of CETP inhibition with anacetrapib $100 \mathrm{mg}$ versus placebo among 30,449 individuals with ASCVD. The HDL-C level was increased by $104 \%$ and non-HLD-C was reduced by $18 \%$ in patients treated with anacetrapib. There was a significant $9 \%$ reduction of coronary death, MI, or coronary revascularization with anacetrapib compared to placebo after the median of 4.1 years of follow-up (10.8\% vs $11.8 \%, P=0.004)$ and the effect appears to be greater in later years of treatment ${ }^{31)}$. The mean level of HDL-C was higher in the anacetrapib group by $43 \mathrm{mg} / \mathrm{dL}$; however, anacetrapib also reduced non-HDL-C levels, which may be enough to explain the $11 \%$ risk reduction in coronary death or MI with anacetrapib. Therefore, the clinical relevance of increasing HDL-C levels remains uncertain. Since the benefit of anacetrapib was relatively modest, the trial sponsor decided not to pursue this drug; however, the trial provided important clinical evidence that moved the field forward.

\section{Diabetes and Heart Failure}

The pathogenesis of diabetes and atherosclerosis are closely linked, and the metabolic abnormalities caused by diabetes induce vascular dysfunction that predisposes diabetic patients to atherosclerosis. As such, diabetes is an established risk factor for CV disease; however, until recently, the CV safety and efficacy of antihyperglycemic drugs remained uncertain, and some have even been shown to be harmful. With the changes in regulatory guidance in 2008 which mandated the developers of novel antihyperglycemic agents to demonstrate CV safety, numerous CV trials have been conducted. This has generated a wealth of data and expanded the focus of the treatment of diabetes from a mere blood glucose control to the prevention of macro- and microvascular complications and improvement in mortality.

Dipeptidyl-peptidase IV (DPP-4) inhibitors lower blood glucose by inhibiting the degradation of the incretins glucagon-like peptide-1 (GLP-1) and glucose-dependent insulinotropic peptide (GIP). In the SAVOR-TIMI 53 trial, the CV safety and efficacy of DPP-4 inhibitor saxagliptin was evaluated by randomly assigning 16,492 patients with type 2 diabetes with or at risk of CV events to saxagliptin 5 $\mathrm{mg}$ daily or placebo ${ }^{32)}$. Although saxagliptin improved glycemic control (HbA1c $7.7 \%$ vs. $7.9 \% p<0.001$ ), saxagliptin neither reduced nor increased the risk of the primary composite endpoint of $\mathrm{CV}$ death, MI, or ischemic stroke when added to standard of care in patients with type 2 diabetes. Previous pooled data from the phase $2 b / 3$ studies of saxagliptin and other development programs of DPP-4 inhibitors have shown that patients treated with DPP-4 inhibitors had more beneficial CV effects than control patients. These discordant findings highlight the importance of conducting properly powered, well-conducted studies with appropriate adjudication procedures to provide scientific evidence to protect patients. The trial also demonstrated a higher incidence of hospitalization for heart failure (HF), which was a pre-defined, adjudicated endpoint. This was an unexpected finding for which mechanisms are unknown at this moment; however, this result has highlighted the important interlink between diabetes and HF.

Sodium-glucose cotransporter 2 (SGLT2) inhibitors are a newer class of antihyperglycemic drug. They block the reabsorption of filtered glucose and sodium by inhibiting the SGLT2 receptor located in the proximal tubule of the kidney. The DECLARETIMI 58 trial enrolled 17,160 patients with or at risk of ASCVD. Compared to other SGLT2 inhibitor trials, DECLARE-TIMI 58 was unique in that it included a broad representation of primary and secondary prevention cohorts ${ }^{33)}$. Dapagliflozin improved HbA1c by $0.42 \%$ and reduced body weight by $1.8 \mathrm{~kg}$, 


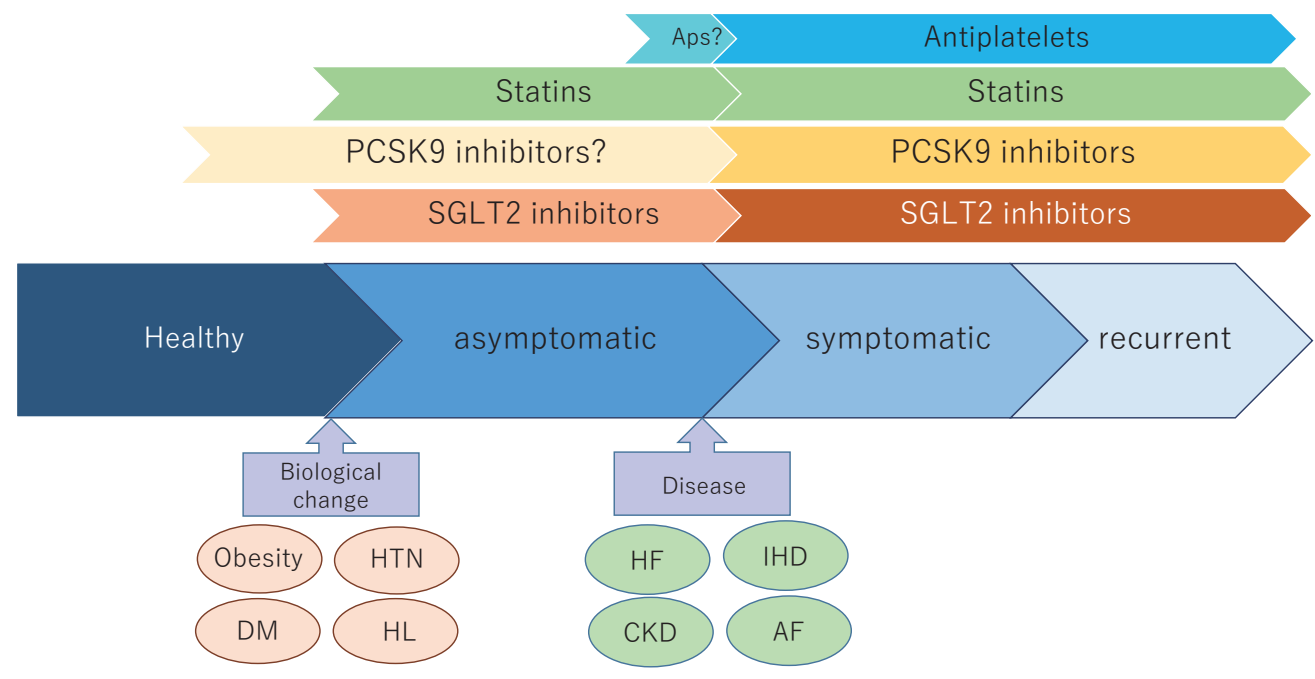

Fig. 1. Progression of atherosclerotic disease and treatment strategy

but, moreover, treatment with dapagliflozin resulted in a $17 \%$ reduction of $\mathrm{CV}$ death/hospitalization for HF (HR 0.83, 95\% CI 0.73-0.95, $p=0.005$ for superiority) and was non-inferior for MACE when compared with placebo (HR 0.93, 95\% CI 0.84-1.03, $p<0.001)$. There was also a $24 \%$ reduction of the renal composite endpoint. The benefit of SGLT2 inhibitors in reducing hospitalization for $\mathrm{HF}$ was unexpected but was also observed in other trials of SGLT2 inhibitors, such as the EMPAREG OUTCOME and CANVAS trials ${ }^{34,35)}$. The treatment effects with SGLT2 inhibitors on hospitalization for $\mathrm{HF}$ appeared early, and were consistent regardless of ejection fraction or HF status ${ }^{36)}$. The robust and consistent effect of SGLT2 inhibitors in reducing HF have led to the investigation in the HF-specific population. The Study to Evaluate the Effect of Dapagliflozin on the Incidence of Worsening Heart Failure or Cardiovascular Death in Patients with Chronic Heart Failure (DAPA-HF) enrolled patients with $\mathrm{HF}$ with reduced ejection fraction (HFrEF) regardless of diabetes status, and demonstrated a $26 \%$ relative risk reduction in the primary composite endpoint of worsening HF or CV death ${ }^{37)}$. The benefit was similar in patients with or without diabetes, and dapagliflozin now has the indication for reducing HF, beyond antihyperglycemic agents. The mechanisms underpinning the beneficial effects of SLGT2 inhibitors on HF remain unclear. Inhibition of the SGLT2 transporter leads to glucosuria and natriuria, thereby decreasing cardiac afterload and preload. Some additional proposed mechanisms include neurohormonal effect and direct effect on myocardium but are thought to be unrelated to their glucose-lowering effects and multifactorial. These unexpected findings have completely shifted the target of diabetes treatment from lower $\mathrm{HbAlc}$ levels to reducing $\mathrm{CV}$ events. It has also generated countless mechanistic and genetic studies in the field of HF and kidney failure, which will likely become drivers for innovative therapeutic inventions in the near future.

\section{Future Directions}

SGLT2 inhibitors, with their unique mechanism, were not the most favored antihyperglycemic agents in the field; however, they have now grown into one of the most promising agents with high therapeutic potential. The current available SGLT2 inhibitor data on $\mathrm{HF}$ are mostly from patients with stable HF; however, the option to use SGLT2 inhibitors in a more acute phase of HF is being sought. Currently ongoing DAPA ACT HF-TIMI 68 is evaluating the safety and efficacy of in-hospital initiation of dapagliflozin in HFrEF patients (LVEF $\leq 40 \%$ ) who have been stabilized during hospitalization for acute HF (www.clinicaltrials.gov NCT04363697).

The discovery of PCSK9 has ushered in an exciting new era for ASCVD prevention and CV risk reduction. ASCVD is a slow progressive disease and unfortunately lasts a lifetime, even after altering lifestyles. An early intervention is essential in delaying the onset of ASCVD, and, as such, Effect of Evolocumab in Patients at High Cardiovascular Risk Without Prior Myocardial Infarction or Stroke (VESALIUS-CV TIMI 66), the trial that will assess the effect of PCSK9 evolocumab on major cardiac events in the primary prevention cohort, is expected to have a huge clinical impact, if proven to be effective (www.clinicaltrials.gov NCT03872401) (Fig. 1). 
On a different axis, there is an excitement surrounding the science with the unprecedented speedy and efficient PCSK9 drug development. Next generation of drugs that are being explored for PCSK9 inhibition are small interfering RNAs (siRNAs). Inclisiran is a chemically synthesized siRNA that specifically inhibits the synthesis of PCSK9 and is expected to decrease LDL-C and CV outcomes. The drug $\left(\right.$ Leqvio $^{\circledR}$ ) was approved by the European Commission (EC) for the treatment of adults with hypercholesterolemia or mixed dyslipidemia in December 2020 based on the results from ORION-9, 10 , and 11 which demonstrated a $44-54 \%$ reduction in LDL-C. Currently, the University of Oxford and the TIMI Study Group's collaborative trial, the HPS-4/TIMI 65 ORION-4 trial, is ongoing to study the long term safety and efficacy of inclisiran in 15,000 ASCVD patients for a duration of approximately five years (www.clinicaltrials.gov NCT03705234). The novelty of this drug is that it will be administered as a subcutaneous injection every six months. In the future, the drug may be used as an LDL-C-lowering vaccine given once a year from a younger age.

\section{Conclusions}

The past decade has dramatically changed the landscape of ASCVD treatment. The successful translation of basic research into practice is a bidirectional process. The TIMI Study Group has been firmly committed to maintaining the high standards of clinical trials that have characterized the group over the past decade. Quality of trials is difficult to assess but must not be forgotten in the era of evidence-based medicine.

\section{Conflict of Interest}

ETK reports receiving honoraria from DaiichiSankyo. SG reports receiving quality fee for the Associate Editor for Circulation, honoraria from Jansen Pharma, Brisotl Myer Squibb, and scholarship grants from Vehicle Racing Commemorative Foundation, the grant-in-aid for NEXT/JSPS KAKENHI 19H03661, AMED grant number A368TS, Bristol-Myers Squibb for independent research suport project (33999603) and a grant from Nakatani Foundation for Advancement of Measuring Technologies in Biomedical Engineering, grant support from Sanofi, Pfizer, and Ono Pharma.

\section{References}

1) Randomised trial of intravenous streptokinase, oral aspirin, both, or neither among 17,187 cases of suspected acute myocardial infarction: ISIS-2. ISIS-2 (Second International Study of Infarct Survival) Collaborative Group. Lancet, 1988; 2: 349-360

2) Collen D and Lijnen HR: Tissue-type plasminogen activator: a historical perspective and personal account. J Thromb Haemost, 2004; 2: 541-546

3) The TIMI Study Grouop: The Thrombolysis in Myocardial Infarction (TIMI) trial. Phase I findings. N Engl J Med, 1985; 312: 932-936

4) Hoshiba Y, Hatakeyama K, Tanabe T, Asada Y and Goto S: Co-localization of von Willebrand factor with platelet thrombi, tissue factor and platelets with fibrin, and consistent presence of inflammatory cells in coronary thrombi obtained by an aspiration device from patients with acute myocardial infarction. J Thromb Haemost, 2006; 4: 114-120

5) Brass S: Cardiovascular biology. Small cells, big issues. Nature, 2001; 409: 145, 147

6) CAPRIE Steering Committee: A randomised, blinded, trial of clopidogrel versus aspirin in patients at risk of ischaemic events (CAPRIE). Lancet, 1996; 348: 13291339

7) Sabatine MS, Cannon CP, Gibson CM, Lopez-Sendon JL, Montalescot G, Theroux P, Claeys MJ, Cools F, Hill $\mathrm{KA}$, Skene AM, McCabe $\mathrm{CH}$, Braunwald E, for the CLARITY-TIMI 28 Investigators: Addition of clopidogrel to aspirin and fibrinolytic therapy for myocardial infarction with ST-segment elevation. N Engl J Med, 2005; 352: 1179-1189

8) Vogel B, Claessen BE, Arnold SV, Chan D, Cohen DJ, Giannitsis E, Gibson CM, Goto S, Katus HA, Kerneis M, Kimura T, Kunadian V, Pinto DS, Shiomi H, Spertus JA, Steg PG and Mehran R: ST-segment elevation myocardial infarction. Nat Rev Dis Primers, 2019; 5: 39

9) Mega JL, Close SL, Wiviott SD, Shen L, Hockett RD, Brandt JT, Walker JR, Antman EM, Macias W, Braunwald E and Sabatine MS: Cytochrome p-450 polymorphisms and response to clopidogrel. N Engl J Med, 2009; 360: 354-362

10) Wiviott SD, Braunwald E, McCabe CH, Montalescot G, Ruzyllo W, Gottlieb S, Neumann FJ, Ardissino D, De Servi S, Murphy SA, Riesmeyer J, Weerakkody G, Gibson CM, Antman EM, for the TRITON-TIMI 38 Investigators: Prasugrel versus clopidogrel in patients with acute coronary syndromes. N Engl J Med, 2007; 357: 2001-2015

11) Coughlin SR: Thrombin signalling and protease-activated receptors. Nature, 2000; 407: 258-264

12) Morrow DA, Braunwald E, Bonaca MP, Ameriso SF, Dalby AJ, Fish MP, Fox KA, Lipka LJ, Liu X, Nicolau JC, Ophuis AJ, Paolasso E, Scirica BM, Spinar J, Theroux P, Wiviott SD, Strony J, Murphy SA, for the TRA 2P-TIMI 50 Steering Committee and Investigators: Vorapaxar in the secondary prevention of atherothrombotic events. $\mathrm{N}$ Engl J Med, 2012; 366: 1404-1413

13) Bonaca MP, Bhatt DL, Cohen M, Steg PG, Storey RF, Jensen EC, Magnani G, Bansilal S, Fish MP, Im K, 
Bengtsson O, Oude Ophuis T, Budaj A, Theroux P, Ruda M, Hamm C, Goto S, Spinar J, Nicolau JC, Kiss RG, Murphy SA, Wiviott SD, Held P, Braunwald E, Sabatine MS, for the PEGASUS-TIMI 54 Steering Committee and Investigators: Long-term use of ticagrelor in patients with prior myocardial infarction. N Engl J Med, 2015; 372: 1791-1800

14) Mega JL, Braunwald E, Wiviott SD, Bassand JP, Bhatt DL, Bode C, Burton P, Cohen M, Cook-Bruns N, Fox KA, Goto S, Murphy SA, Plotnikov AN, Schneider D, Sun X, Verheugt FW, Gibson CM, for the ATLAS ACS2TIMI 51 Investigators: Rivaroxaban in patients with a recent acute coronary syndrome. N Engl J Med, 2012; 366: 9-19

15) Eikelboom JW, Connolly SJ and Yusuf S: Rivaroxaban in Stable Cardiovascular Disease. N Engl J Med, 2018; 378: 397-398

16) Hioki H, Watanabe $Y$, Kozuma K, Kataoka A, Yashima F, Naganuma T, Araki M, Tada N, Shirai S, Yamanaka F, Mizutani K, Tabata M, Takagi K, Ueno H, Yamamoto M, Hayashida K and OCEAN-TAVI Investigators: Shortterm dual anti-platelet therapy decreases long-term cardiovascular mortality after transcatheter aortic valve replacement. Heart Vessels, 2021; 36: 252-259

17) Hahn JY, Song YB, Oh JH, Chun WJ, Park YH, Jang WJ, Im ES, Jeong JO, Cho BR, Oh SK, Yun KH, Cho DK, Lee JY, Koh YY, Bae JW, Choi JW, Lee WS, Yoon HJ, Lee SU, Cho JH, Choi WG, Rha SW, Lee JM, Park TK, Yang $\mathrm{JH}$, Choi JH, Choi SH, Lee SH, Gwon HC and for the SMART-CHOICE Investigators: Effect of P2Y12 Inhibitor Monotherapy vs Dual Antiplatelet Therapy on Cardiovascular Events in Patients Undergoing Percutaneous Coronary Intervention: The SMARTCHOICE Randomized Clinical Trial. JAMA, 2019; 321: 2428-2437

18) Mehran R, Baber U, Sharma SK, Cohen DJ, Angiolillo DJ, Briguori C, Cha JY, Collier T, Dangas G, Dudek D, Dzavik V, Escaned J, Gil R, Gurbel P, Hamm CW, Henry T, Huber K, Kastrati A, Kaul U, Kornowski R, Krucoff M, Kunadian V, Marx SO, Mehta SR, Moliterno D, Ohman EM, Oldroyd K, Sardella G, Sartori S, Shlofmitz R, Steg PG, Weisz G, Witzenbichler B, Han YL, Pocock S and Gibson CM: Ticagrelor with or without Aspirin in High-Risk Patients after PCI. N Engl J Med, 2019; 381: 2032-2042

19) Endo A, Tsujita $Y$, Kuroda $M$ and Tanzawa K: Inhibition of cholesterol synthesis in vitro and in vivo by ML-236A and ML-236B, competitive inhibitors of 3-hydroxy-3methylglutaryl-coenzyme A reductase. European journal of biochemistry, 1977; 77: 31-36

20) Endo A, Tsujita $Y$, Kuroda $M$ and Tanzawa K: Effects of ML-236B on cholesterol metabolism in mice and rats: lack of hypocholesterolemic activity in normal animals. Biochimica et biophysica acta, 1979; 575: 266-276

21) Endo A: A gift from nature: the birth of the statins. Nature medicine, 2008; 14: 1050-1052

22) Cannon CP, Braunwald E, McCabe CH, Rader DJ, Rouleau JL, Belder R, Joyal SV, Hill KA, Pfeffer MA, Skene AM, for the Pravastatin or Atorvastatin Evaluation and Infection Therapy-Thrombolysis in Myocardial Infarction 22 Investigators. Engl J Med, 2004; 350: 1495-
1504

23) Cannon CP, Blazing MA, Giugliano RP, McCagg A, White JA, Theroux P, Darius H, Lewis BS, Ophuis TO, Jukema JW, De Ferrari GM, Ruzyllo W, De Lucca P, Im K, Bohula EA, Reist C, Wiviott SD, Tershakovec AM, Musliner TA, Braunwald E, Califf RM, for the IMPROVE-IT Investigators: Ezetimibe Added to Statin Therapy after Acute Coronary Syndromes. N Engl J Med, 2015; 372: 2387-2397

24) Abifadel M, Varret M, Rabes JP, Allard D, Ouguerram K, Devillers M, Cruaud C, Benjannet S, Wickham L, Erlich D, Derre A, Villeger L, Farnier M, Beucler I, Bruckert E, Chambaz J, Chanu B, Lecerf JM, Luc G, Moulin P, Weissenbach J, Prat A, Krempf M, Junien C, Seidah NG and Boileau C: Mutations in PCSK9 cause autosomal dominant hypercholesterolemia. Nat Genet, 2003; 34: 154-156

25) Sabatine MS, Giugliano RP, Keech AC, Honarpour N, Wiviott SD, Murphy SA, Kuder JF, Wang H, Liu T, Wasserman SM, Sever PS, Pedersen TR, for the FOURIER Steering Committee and Investigators: Evolocumab and Clinical Outcomes in Patients with Cardiovascular Disease. N Engl J Med, 2017; 376: 17131722

26) Wiviott SD, Cannon CP, Morrow DA, Ray KK, Pfeffer MA, Braunwald E and Investigators PI-T: Can lowdensity lipoprotein be too low? The safety and efficacy of achieving very low low-density lipoprotein with intensive statin therapy: a PROVE IT-TIMI 22 substudy. J Am Coll Cardiol, 2005; 46: 1411-1416

27) Wiviott SD, Mohanavelu S, Raichlen JS, Cain VA, Nissen SE and Libby P: Safety and efficacy of achieving very low low-density lipoprotein cholesterol levels with rosuvastatin $40 \mathrm{mg}$ daily (from the ASTEROID Study). Am J Cardiol, 2009; 104: 29-35

28) Sabatine MS, Wiviott SD, Im K, Murphy SA and Giugliano RP: Efficacy and Safety of Further Lowering of Low-Density Lipoprotein Cholesterol in Patients Starting With Very Low Levels: A Meta-analysis. JAMA Cardiol, 2018; 3: 823-828

29) Giugliano RP, Pedersen TR, Park JG, De Ferrari GM, Gaciong ZA, Ceska R, Toth K, Gouni-Berthold I, LopezMiranda J, Schiele F, Mach F, Ott BR, Kanevsky E, Pineda AL, Somaratne R, Wasserman SM, Keech AC, Sever PS, Sabatine MS and FOURIER Investigators: Clinical efficacy and safety of achieving very low LDLcholesterol concentrations with the PCSK9 inhibitor evolocumab: a prespecified secondary analysis of the FOURIER trial. Lancet, 2017; 390: 1962-1971

30) Giugliano RP, Wiviott SD, Blazing MA, De Ferrari GM, Park JG, Murphy SA, White JA, Tershakovec AM, Cannon CP and Braunwald E: Long-term Safety and Efficacy of Achieving Very Low Levels of Low-Density Lipoprotein Cholesterol: A Prespecified Analysis of the IMPROVE-IT Trial. JAMA Cardiol, 2017; 2: 547-555

31) HPS3/TIMI55-REVEAL Collaborative Group, Bowman L, Hopewell JC, Chen F, Wallendszus K, Stevens W, Collins R, Wiviott SD, Cannon CP, Braunwald E, Sammons E and Landray MJ: Effects of Anacetrapib in Patients with Atherosclerotic Vascular Disease. N Engl J Med, 2017; 377: 1217-1227 
32) Scirica BM, Bhatt DL, Braunwald E, Steg PG, Davidson J, Hirshberg B, Ohman P, Frederich R, Wiviott SD, Hoffman EB, Cavender MA, Udell JA, Desai NR, Mosenzon O, McGuire DK, Ray KK, Leiter LA, Raz I, for the SAVOR-TIMI 53 Steering Committee and Investigators: Saxagliptin and cardiovascular outcomes in patients with type 2 diabetes mellitus. N Engl J Med, 2013; 369: 1317-1326

33) Wiviott SD, Raz I, Bonaca MP, Mosenzon O, Kato ET, Cahn A, Silverman MG, Zelniker TA, Kuder JF, Murphy SA, Bhatt DL, Leiter LA, McGuire DK, Wilding JPH, Ruff CT, Gause-Nilsson IAM, Fredriksson M, Johansson PA, Langkilde AM, Sabatine MS, for the DECLARETIMI 58 Investigators: Dapagliflozin and Cardiovascular Outcomes in Type 2 Diabetes. N Engl J Med, 2019; 380: 347-357

34) Zinman B, Lachin JM and Inzucchi SE: Empagliflozin, Cardiovascular Outcomes, and Mortality in Type 2 Diabetes. N Engl J Med, 2016; 374: 1094

35) Neal B, Perkovic V and Matthews DR: Canagliflozin and Cardiovascular and Renal Events in Type 2 Diabetes. $\mathrm{N}$
Engl J Med, 2017; 377: 2099

36) Kato ET, Silverman MG, Mosenzon O, Zelniker TA, Cahn A, Furtado RHM, Kuder J, Murphy SA, Bhatt DL, Leiter LA, McGuire DK, Wilding JPH, Bonaca MP, Ruff CT, Desai AS, Goto S, Johansson PA, Gause-Nilsson I, Johanson P, Langkilde AM, Raz I, Sabatine MS and Wiviott SD: Effect of Dapagliflozin on Heart Failure and Mortality in Type 2 Diabetes Mellitus. Circulation, 2019; 139: 2528-2536

37) McMurray JJV, Solomon SD, Inzucchi SE, Kober L, Kosiborod MN, Martinez FA, Ponikowski P, Sabatine MS, Anand IS, Belohlavek J, Bohm M, Chiang CE, Chopra VK, de Boer RA, Desai AS, Diez M, Drozdz J, Dukat A, Ge J, Howlett JG, Katova T, Kitakaze M, Ljungman CEA, Merkely B, Nicolau JC, O’Meara E, Petrie MC, Vinh PN, Schou M, Tereshchenko S, Verma S, Held C, DeMets DL, Docherty KF, Jhund PS, Bengtsson O, Sjostrand M, Langkilde AM, DAPA-HF Trial Committees and Investigators: Dapagliflozin in Patients with Heart Failure and Reduced Ejection Fraction. N Engl J Med, 2019; 381: 1995-2008 